\title{
Duloxetine Increases Serotonin and Norepinephrine Availability in Healthy Subjects: A Double-Blind, Controlled Study
}

\author{
Stephan A Chalon*,', Luc-André Granier', François R Vandenhende', Peter R Bieck², Frank P Bymaster², \\ Melissa J Joliat ${ }^{2}$, Christine Hirth ${ }^{3}$, William Z Potter ${ }^{2}$ \\ 'Lilly Research Laboratories, Mont-Saint-Guibert, Belgium; 'Lilly Research Laboratories, Indianapolis, IN, USA; ' Université Louis Pasteur, \\ Strasbourg, France
}

\begin{abstract}
Evidence suggests that compounds that increase the synaptic availability of more than one neurotransmitter have greater efficacy in the treatment of depression than single-acting drugs. Preclinical studies indicate that duloxetine acts to inhibit serotonin (5-HT) and norepinephrine (NE) transporters. The ability of duloxetine to alter 5-HT and NE reuptake was tested in 12 healthy male subjects. Placebo, desipramine $50 \mathrm{mg}$ b.i.d., and duloxetine $(80 \mathrm{mg}$ q.d. or $60 \mathrm{mg}$ b.i.d.) were compared in a randomized, double-blind, threeperiod crossover study in 12 healthy male subjects. Whole-blood 5-HT, urinary excretion of NE and major metabolites, and TYR PD 30 (IV tyramine pressor dose needed to increase systolic blood pressure by $30 \mathrm{mmHg}$ ) were measured at steady state. Vital signs were measured periodically. Duloxetine affected 5-HT reuptake, with whole-blood 5-HT depletion vs placebo (80 mg q.d.: $p=0.07 ; 60 \mathrm{mg}$ b.i.d.: $p=0.02$; combined regimens: $p=0.01$ ). Cardiovascular changes reflecting increased sympathetic tone were observed with both duloxetine and desipramine, and both treatments significantly decreased whole body NE turnover $(p<0.01)$. Duloxetine and desipramine were associated with similar mean increases in fractional extraneuronal NE concentration, although these changes did not reach statistical significance. TYR $\mathrm{PD}_{30}$ increased significantly with desipramine dosing $(p<0.0 \mathrm{I})$. In conclusion, whole-blood measurements confirm that duloxetine inhibits platelet 5-HT uptake in vivo. Urinary and cardiovascular measurements suggest that duloxetine has an effect on NE synthesis and turnover, indicative of NE reuptake inhibition. The lack of a detectable impact of duloxetine on TYR PD 30 suggests that this may not be the most sensitive indirect measure of NE reuptake when assessing dual reuptake inhibitors. Neuropsychopharmacology (2003) 28, I685-1693, advance online publication, 28 May 2003; doi: I 0. I 038/sj.npp. I 300209
\end{abstract}

Keywords: serotonin; norepinephrine; antidepressive agents; neurotransmitter uptake inhibitors

\section{Introduction}

Increasing synaptic availability of serotonin (5-HT) and/or norepinephrine (NE) is a well-established mechanism of action of many antidepressants. Compounds that act to increase the availability of both these neurotransmitters are believed to have greater efficacy than single-acting drugs. Duloxetine (LY248686; (+)- $N$-methyl-3-(1-naphthalenyloxy)-2-thiophenepropanamine) is a compound currently being investigated as an antidepressant medication that,

This study was supported by a grant from Lilly Research Laboratories, Indianapolis, IN, USA.

*Correspondence: Dr S Chalon, Department of Clinical Pharmacology, Lilly Development Centre S.A., Parc Scientifique de Louvain-La-Neuve, Rue Granbonpré II, 1348 Mont-Saint-Guibert, Belgium, Tel: + 32 10476440, Fax: + 32 10476475, E-mail: chalon_stephane_a@lilly.com Received 18 December 2002; revised 19 March 2003; accepted 21 March 2003

Online publication: 4 April 2003 at http://www.acnp.org/citations/ Npp040402474/default.pdf according to preclinical data, inhibits monoamine transporters (formerly referred to as uptake carriers) for both 5HT and NE (Wong, 1998; Wong and Bymaster, 2002). Duloxetine blocks binding of $\left[{ }^{3} \mathrm{H}\right]$ paroxetine to the human 5-HT transporter (5-HTT) and binding of $\left[{ }^{3} \mathrm{H}\right]$ nisoxetine to the human NE transporter (NET), with $K_{\mathrm{i}}$ values of 0.8 and $7.5 \mathrm{nM}$, respectively, suggesting that duloxetine is relatively balanced in its inhibition of 5-HT and NE reuptake. In the same in vitro experiment, similar measurements with venlafaxine, a marketed dual reuptake inhibitor, yielded $K_{\mathrm{i}}$ values of $82 \mathrm{nM}$ for 5-HTT and $2480 \mathrm{nM}$ for NET (Bymaster et al, 2001). Duloxetine activity in rat brain is consistent with dual reuptake inhibition, and with an effect on central monoamine reuptake (Bymaster et al, 2001; Engleman et al, 1995; Katoh et al, 1995; Kihara and Ikeda, 1995). Duloxetine exhibits linear pharmacokinetics in humans, with respect to dose and treatment duration (Sharma et al, 2000).

A multiple-dose escalation study of healthy male and female subjects found that doses of duloxetine in the range of $40-80 \mathrm{mg} / \mathrm{day}$ induced drug-related adverse events that 
are typical of a potent 5-HT reuptake inhibitor (Lilly Research Laboratories, Study F1J-BD-HMAR, data on file). Duloxetine's inhibitory effects on 5-HT reuptake have also been convincingly demonstrated by measurement of wholeblood 5-HT levels in healthy subjects (Turcotte et al, 2001).

At doses of duloxetine $\geqslant 60 \mathrm{mg} /$ day, in addition to effects consistent with 5-HT reuptake inhibition, healthy subjects experienced drug-related effects (including increased standing heart rate (HR) and sweating) similar to those seen with typical NE reuptake inhibitors (Sharma et al, 2000; Turcotte et al, 2001). Although the effects of duloxetine in healthy subjects are consistent with dual mechanisms of action, effects on NE have not been directly demonstrated in humans.

Methods to assess the effects of a drug on the NE axis include measurement of urinary excretion of $\mathrm{NE}$ and its major metabolites (vanillomandelic acid, 3-methoxy-4hydroxy-phenylglycol, and normetanephrine; VMA, MHPG, and $\mathrm{NM}$, respectively) and evaluation of tyramine sensitivity using the tyramine pressor test. Decreased tyramine sensitivity has been reported for several NE reuptake inhibitors (Reimann et al, 1993), including tricyclic antidepressants such as desipramine (McEwen, 1977). Using tyramine bolus injection after 7 or 14 days of treatment with duloxetine up to $60 \mathrm{mg} / \mathrm{day}$ in healthy young males, Turcotte et al (2001) were unable to detect a significant change in tyramine-induced systolic BP elevation, whereas they did demonstrate the 5-HT reuptake blocking property of duloxetine with doses as low as $20 \mathrm{mg} /$ day. These authors hypothesized that an effect on NE reuptake could occur at doses higher than $60 \mathrm{mg} /$ day. However, the influence of such doses of duloxetine on NE reuptake has not been evaluated until this study.

The present study was designed to assess whether two dose regimens of duloxetine, within a therapeutic range targeted for depression, could influence peripheral NE reuptake in healthy volunteers at steady-state plasma concentration. Assessment of NE reuptake was based primarily on two tests: the intravenous tyramine pressor test and measurement of urinary excretion of NE and its metabolites. Heart rate and blood pressure data were also collected throughout the study. For this study, desipramine, a tricyclic agent with a $K_{\mathrm{i}}$ value $\left(\left[{ }^{3} \mathrm{H}\right]\right.$ nisoxetine binding) for the human NET of $0.63 \mathrm{nM}$ (Owens et al, 1997), was used as a positive control.

\section{Methods}

\section{Study Design}

This was a randomized, double-blind, three-period, fourtreatment, cross-over study. All subjects $(n=12)$ received placebo b.i.d. (negative control), desipramine $50 \mathrm{mg}$ b.i.d. (100 mg/day) (positive control), and either one of two duloxetine regimens $(80 \mathrm{mg} /$ day q.d., or $60 \mathrm{mg}$ b.i.d. ( $120 \mathrm{mg} /$ day) $n=6 \mathrm{each}$ ) during the three consecutive 7 day treatment periods. The order of the possible treatment regimens for each subject was assigned randomly, and the washout period lasted at least 10 days between each dosing period.

A local ethics committee (Hôpital Boucicaut, Paris, France) reviewed and approved the protocol. The study was monitored and conducted according to Good Clinical Practices. All subjects provided written informed consent prior to the administration of study drug or any study procedure. The subjects were all evaluated at the AsterCephac study center (Paris, France).

Subjects reported to the study center at least $12 \mathrm{~h}$ before dosing and remained there until $30 \mathrm{~h}$ after receiving the final dose. Alcohol, tobacco, caffeine-containing drinks, and strenuous exercise were prohibited from $48 \mathrm{~h}$ prior to admission to the study unit until $48 \mathrm{~h}$ after the final drug dose. Apart from dextromethorphan (which was used for CYP2D6 phenotyping at screening), all medications other than the study drug were prohibited from 15 days (over-thecounter medications) or 30 days (prescription medications) before admission.

Duloxetine and desipramine were administered as $20 \mathrm{mg}$ and $25 \mathrm{mg}$ capsules, respectively; blinding was maintained using standard double-dummy techniques. Because duloxetine and desipramine capsules were not identical in appearance, all subjects received eight capsules twice daily to maintain blinding with the various dosing regimens; for example, when active duloxetine capsules were taken, subjects also took desipramine placebo capsules. Capsules were given in a sitting position at approximately 08.00 and $20.00 \mathrm{~h}$ from Day 1 to Day 6, and a final dose at approximately $08.00 \mathrm{~h}$ on Day 7. Duloxetine $80 \mathrm{mg} /$ day q.d. was given as a morning dose.

\section{Subjects}

Subjects were excluded if they had any clinically significant disease (according to clinical history, physical examination, and routine hematology/clinical chemistry tests). They were specifically excluded if they had abnormal electrocardiograms or more than a single ventricular premature complex per hour during a 24-h Holter monitor observation period obtained within 20 days prior to the first study drug administration. Subjects were excluded if their supine resting BP was $>140 / 90 \mathrm{mmHg}$, or if their cigarette consumption was $\geqslant 5$ cigarettes/day. As desipramine is primarily metabolized through CYP2D6, poor metabolizers (defined by a dextromethorphan/dextrorphan ratio $\geqslant 0.3$ in an 8-h urine collection) were excluded to avoid potential accumulation during the study washout phases. A total of 12 subjects were randomized into the study. This number provided $94 \%$ power to detect at the two-sided 5\% level a $2 \mathrm{mg}$ mean difference in tyramine $\mathrm{ED}_{30}$ between placebo and duloxetine (Pace et al, 1988).

\section{Measurements and Data Analysis}

Pharmacokinetics. Blood samples $(10 \mathrm{ml})$ for measurement of duloxetine and desipramine plasma concentrations were collected by venipuncture into heparinized tubes immediately before dosing on the mornings of Days 5, 6, and 7 and at the same time on Day 8. Samples were collected immediately before and after completion of the tyramine test (conducted from 09:30 to 10:30 h on Days 7 and 8), were centrifuged within $20 \mathrm{~min}$ of sampling, and plasma was stored at $-20^{\circ} \mathrm{C}$ until analyzed.

Plasma samples were analyzed for duloxetine using a validated LC/MS/MS method at Oneida Research Services 
(Whitesboro, NY, USA). Duloxetine and the stable label internal standard were extracted from the plasma using a C8 solid phase extraction column. The validated range was $0.5-$ $100 \mathrm{ng} / \mathrm{ml}$.

Samples were analyzed for desipramine using a validated gas chromatography method at PPD Development laboratories (Richmond, VA, USA). Desipramine and the internal standard were extracted from plasma into a 2-butanol/ hexane mixture. The extract was analyzed by gas chromatography with nitrogen-phosphorous detection. The validated range was $0.5-100 \mathrm{ng} / \mathrm{ml}$.

The achievement and maintenance of steady-state conditions were tested after duloxetine and desipramine daily administration using a repeated-measures analysis of variance (ANOVA) of predose concentrations recorded from Day 5 to Day 7. Linear contrast $t$-tests were performed on successive administration days for the detection of a lack of steady-state conditions.

Whole-blood 5-HT. A 2-ml blood sample was obtained before dosing on Days 1 and 7 (at approximately $08.00 \mathrm{~h}$ ), was frozen on dry ice, and then stored in a $-60^{\circ} \mathrm{C}$ freezer until assayed. The procedure for extraction of 5-HT and precipitation of protein in whole blood was according to the published method of Marshall et al (1987). Recovery of a 5HT standard from whole blood was $70 \%$. Levels of 5-HT were quantified by HPLC with electrochemical detection according to the method of Li et al (1998).

Mean whole-blood 5-HT concentrations obtained on Day 7 were compared across treatment groups with a repeatedmeasures analysis of covariance. The model included the baseline measure obtained at Day 1 as covariate and terms for the sequence, period, and treatment. Comparisons between treatments were made with a $t$-test.

Urinary excretion of NE and metabolites. Urine specimens $(24 \mathrm{~h})$ were collected on Days 5 and 6, using 21 polyethylene containers containing $10 \mathrm{ml}$ of $6 \mathrm{~mol} / \mathrm{l} \mathrm{HCl}$. The volume of each specimen was measured and aliquots $(1-5 \mathrm{ml})$ were stored frozen at $-20^{\circ} \mathrm{C}$ until analyzed using validated assays (Institut de Chimie Biologique, Université Louis Pasteur, Strasbourg, France). In addition to NE and its metabolites, creatinine concentration was measured for each 24-h urine collection. Complete 24-h urine collections were defined as those where total urinary creatinine was $>1000 \mathrm{mg}$.

Norepinephrine and normetanephrine: Urinary NM and free NE were determined using an HPLC method with electrochemical detection and on-line purification (Volin, 1994). Mobile phase composition and detector voltage were changed between the free NE and NM assays.

3-Methoxy-4-hydroxy-phenylglycol: Determination of urinary MHPG was performed as described by Bourdeaux et al (1995).

Vanillomandelic acid: Quantification of urinary VMA was performed using a liquid chromatographic method (Gironi et al, 1988).

Individual concentrations for each of the parameters assayed in urine were summed up over the 48-h measure- ment period (Days 5 and 6). Three urinary indices were calculated: $\mathrm{NE}$ whole body turnover $(\mathrm{NE}+\mathrm{NM}+\mathrm{V}$ $\mathrm{MA}+\mathrm{MHPG})$, the fractional extraneuronal concentration of $\mathrm{NE}$ derived from the ratio $[(\mathrm{NE}+\mathrm{NM}) /(\mathrm{NE}+\mathrm{NM}+\mathrm{V}-$ $\mathrm{MA}+\mathrm{MHPG})]$, and extraneuronal/intraneuronal metabolism $[(\mathrm{NE}+\mathrm{NM}) /(\mathrm{VMA}+\mathrm{MHPG})]$. Mean 48 -h values obtained for these indices were compared across treatment groups with repeated-measures ANOVA.

Cardiovascular parameters. Systolic and diastolic BP and $\mathrm{HR}$, in supine and standing resting positions, were recorded on Day 6 at $0 \mathrm{~h}$ (predose), and at 3 and $6 \mathrm{~h}$ postdose. On Days 7 and 8 , these parameters were measured before the tyramine test. Twelve lead ECG measurements were made from Days 1 to 7 at $0 \mathrm{~h}$ (predose) and at $6 \mathrm{~h}$ postdose, as well as on Day 8 at approximately 08.00 and $14.00 \mathrm{~h}$.

Mean HR and BP obtained on Day 6 were compared across treatments using repeated-measures ANOVA to analyze data collected at three time points $(0,3$, and $6 \mathrm{~h}$ after dosing).

Intravenous tyramine pressor test. The pressor response to i.v. bolus tyramine injection was determined on Days 7 and 8 (at approximately 2 and $26 \mathrm{~h}$ after the last study dose, respectively). At $08.30 \mathrm{~h}$, a catheter was inserted into the subject's suitable forearm vein for sterile infusion of $0.9 \%$ saline solution, and a blood pressure cuff was placed on the contralateral arm. Subjects then rested quietly in a slightly darkened room for at least $45 \mathrm{~min}$ to allow for $\mathrm{BP}$ equilibration. The test was initiated at $09.30 \mathrm{~h}$, after obtaining at least 3 min of stable BP and HR measurements. Tyramine was administered in incremental challenge doses within $30 \mathrm{~s}$ (via a three-way stopcock), using doses ranging from 0.5 to $46.0 \mathrm{mg}$. Each injection of tyramine was immediately followed by a $3 \mathrm{ml}$ saline injection to flush out the catheter. The initial three doses $(0.5,1$, and $2 \mathrm{mg})$ were systematically administered at the beginning of the test. The physician was then free to decide whether 2 or $4 \mathrm{mg}$ increments were subsequently needed, depending on the magnitude of the observed response. A minimum of four doses per test was required in order to assess the subject's response. Placebo injections of saline were administered randomly at least once to each subject during the course of each test. Blood pressure and HR were measured on the noncannulated arm (with the subject in the supine position) every minute for at least $5 \mathrm{~min}$ after each injection. The maximum systolic blood pressure (SBP) recorded after the administration of each dose was selected for data interpretation. The tyramine injection/pressor response assay was repeated at 5- to 10-min intervals (after SBP had returned to within $5 \mathrm{mmHg}$ of baseline) for each increasing dose. Incremental tyramine doses were administered until the SBP after injection had increased to 30$45 \mathrm{mmHg}$ above baseline.

For each individual tyramine pressor test, a linear regression through zero $(Y=\alpha \star$ dose $)$ was applied to relate the peak change from baseline in SBP ( $\mathrm{mmHg}$ ) to the tyramine bolus dose level $(\mathrm{mg})$. The expected tyramine pressor dose $(\mathrm{mg})$ required to produce a $30-\mathrm{mmHg}$ increase from basal SBP (TYR $\mathrm{PD}_{30}$ ) was predicted as TYR $\mathrm{PD}_{30}=30 / \alpha$ from the fit of that model. The maximum 
administered tyramine dose was used as the TYR $\mathrm{PD}_{30}$ estimate when the predicted TYR $\mathrm{PD}_{30}$ was at least $20 \%$ larger than the maximum dose. Mean TYR $\mathrm{PD}_{30}$ values were compared between treatments on Days 7 and 8, using repeated-measures ANOVA. The level of significance for these analyses was defined as $p<0.05$.

Safety parameters. Subjects were queried regarding possible adverse events noted during their participation in the study. Severity, likelihood of association to study drug, and details regarding resolution of the events were documented in the subjects' records.

Comparisons were made between the subjects' adverse event reports during each arm of drug dosing and their placebo treatment adverse events.

\section{Results}

A total of 12 healthy male subjects (including three cigarette smokers), ranging in age from 23 to 38 years (mean: 32 years), were included in this study. Their weight ranged from 56 to $92 \mathrm{~kg}$ (mean: $74 \mathrm{~kg}$ ). Of the 12 randomized subjects, 11 successfully completed all dosing periods. One subject discontinued for personal reasons after completing the first dosing period (randomized to placebo). As this subject was not replaced, 11, five, and six subjects were actually treated with desipramine, duloxetine $80 \mathrm{mg} /$ day, and duloxetine $120 \mathrm{mg} /$ day, respectively.

All active drugs reached steady-state conditions by Day 5 . Mean predose plasma concentrations (geometric means) measured on Day 5 were 19, 46, and $41 \mathrm{ng} / \mathrm{ml}$ for duloxetine $80 \mathrm{mg} /$ day, duloxetine $120 \mathrm{mg} /$ day, and desipramine, respectively.

\section{Whole-Blood 5-HT}

Mean (SD) blood 5-HT concentration on Day 7 was $1.10 \pm 0.54 \mathrm{nmol} / \mathrm{mL}$ for placebo $(n=12)$. For duloxetine $80 \mathrm{mg} /$ day $(n=5)$, mean blood 5-HT decrease $(-0.44 \pm 0.23 \mathrm{nmol} / \mathrm{ml})$ was not significant $(p=0.07 v s$ placebo). Duloxetine $120 \mathrm{mg} /$ day $(n=6)$ was associated with a significant decrease in mean blood 5-HT $(-0.53 \pm 0.21 \mathrm{nmol} / \mathrm{ml} ; p=0.02)$. A subgroup analysis that considered distinct control panels for the two duloxetine doses confirmed these findings. When the data from the two doses of duloxetine were combined $(n=11)$, a significant decrease was observed compared to placebo $(-0.49 \pm 0.17 \mathrm{nmol} / \mathrm{ml} ; p=0.01)$. Desipramine did not alter mean blood 5 -HT $(-0.01 \pm 0.13 \mathrm{nmol} / \mathrm{ml} ; p=0.95)$ compared to placebo.

\section{Urinary Excretion of NE and Metabolites}

Summary statistics and group comparisons for NE and metabolites are presented in Table 1. Whole body NE turnover (WBT, represented by the sum $\mathrm{NE}+\mathrm{NM}+\mathrm{V}$ $\mathrm{MA}+\mathrm{MHPG}$ ) was significantly decreased with all active treatments $(p<0.01)$. As shown in Table 1 , the effect of desipramine on WBT was accounted for by a decrease in NE and each of the metabolites. In contrast, the effects of duloxetine were primarily related to a decrease in the metabolites, with no changes in NE when compared to placebo. Significant decreases in NM were observed with duloxetine $120 \mathrm{mg} /$ day $(p<0.01)$, while significant decreases in MHPG and VMA were seen at both the 80 and $120 \mathrm{mg} /$ day doses $(p<0.01)$. Parallel increases in the ratios $((\mathrm{NE}+\mathrm{NM}) / \mathrm{WBT})$ and $((\mathrm{NE}+\mathrm{NM}) /(\mathrm{VMA}+\mathrm{MHPG}))$ were not significant with desipramine or duloxetine $80 \mathrm{mg} /$ day ( $p=0.06$ for both treatments). A significant increase was noted for desipramine $v s$ placebo in the NM/VMA ratio $(p=0.04)$; this ratio was not significantly increased with the duloxetine regimens.

\section{Cardiovascular Parameters}

Cardiovascular parameters collected for active treatment groups were compared with placebo to detect drugassociated changes. With the subjects in supine position on Day 6, prior to dosing $(0 \mathrm{~h})$, a significant increase in HR was observed with desipramine $(+15 \mathrm{bpm} v s$ placebo, $p<0.01)$, but not with either of the duloxetine regimens. A significant increase in SBP was observed at $0 \mathrm{~h}$ with duloxetine $80 \mathrm{mg} /$ day $(+9.45 \mathrm{mmHg} v s$ placebo, $p<0.05)$, but no changes in SBP were seen with desipramine or duloxetine $120 \mathrm{mg} /$ day. No significant changes in supine DBP were observed at $0 \mathrm{~h}$ with any of the active regimens. At $3 \mathrm{~h}$ after dosing on Day 6, HR was significantly increased

Table I Urinary Excretion of Norepinephrine and Metabolites

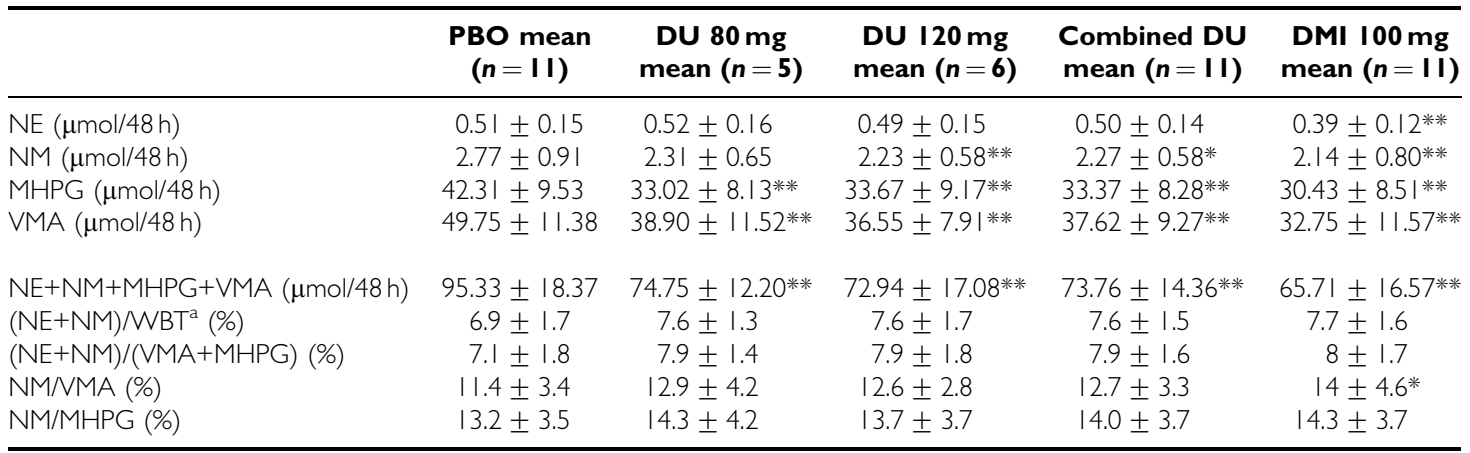

Means are presented $\pm \mathrm{SD}$.

$\mathrm{NE}=$ norepinephrine, $\mathrm{NM}=$ normetanephrine, $\mathrm{MHPG}=3$-methoxy-4-hydroxy-phenylglycol, VMA = vanillomandelic acid.

${ }^{\mathrm{a}} \mathrm{WBT}=$ Whole-body norepinephrine turnover $=(\mathrm{NE}+\mathrm{NM}+\mathrm{MHPG}+\mathrm{VMA}) .{ }^{*} p<0.05, * * p<0.0$ I vs placebo. 
with desipramine $(+9.7 \mathrm{bpm} v$ s placebo, $p<0.01)$, as was SBP $(+9.3 \mathrm{mmHg} \quad v s$ placebo, $p<0.05)$ and DBP $(+6.8 \mathrm{mmHg} v s$ placebo, $p<0.05)$. Neither of the duloxetine regimens produced any significant effect on supine cardiovascular parameters at $3 \mathrm{~h}$ postdose. At $6 \mathrm{~h}$ postdose, an increase in supine $\mathrm{HR}$ was seen with desipramine $(+12.0 \mathrm{bpm} v s$ placebo, $p<0.01)$, but not with either duloxetine dose. None of the active treatments had any significant effect on SBP. An increase in supine DBP was seen at $6 \mathrm{~h}$ with duloxetine $80 \mathrm{mg} /$ day $(+8.6 \mathrm{mmHg} v s$ placebo, $p<0.05$ ), but not with duloxetine $120 \mathrm{mg} /$ day or desipramine.

Mean values for the standing cardiovascular parameters measured at steady state on Day 6 are shown in Figure 1. Prior to dosing $(0 \mathrm{~h})$, a significant elevation in HR $v s$ placebo was observed for the desipramine regimen $(+27.6 \mathrm{bpm}, p<0.01)$, but neither of the duloxetine regimens was associated with significant changes in HR at this time. No significant changes in SBP or DBP were detected with any of the active treatment groups at $0 \mathrm{~h}$. At $3 \mathrm{~h}$ postdosing, standing HR was significantly increased with both desipramine and duloxetine $80 \mathrm{mg} /$ day $(+27.7$, $+20.1 \mathrm{bpm}$, respectively, $v s$ placebo; $p<0.01$ ), but only a modest and highly variable average increase in $\mathrm{HR}$ of $7 \mathrm{bpm}$ $(p=0.16)$ was observed with duloxetine $120 \mathrm{mg} /$ day. A significant increase in SBP was observed with duloxetine
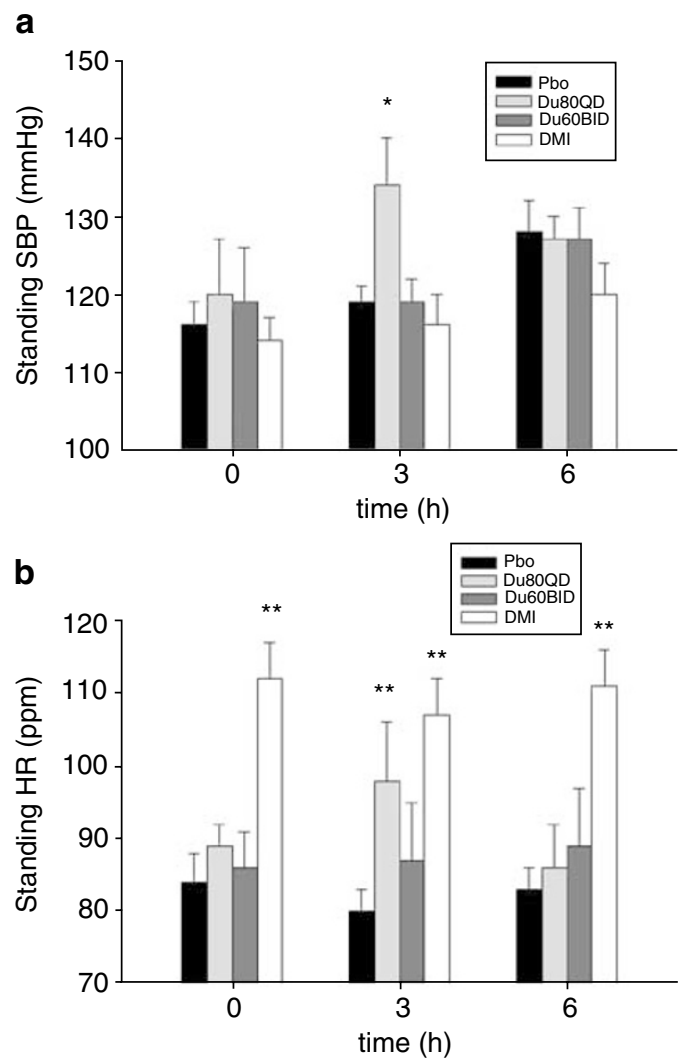

Figure I Mean $( \pm$ SEM) SBP (a) and heart rate (b) obtained in standing position at 0,3 and $6 \mathrm{~h}$ on Day $6 . \mathrm{HR}=$ heart rate, SBP $=$ systolic blood pressure. No significant effect was found on diastolic blood pressure (data not shown) $\mathrm{Pbo}=$ placebo, $\quad$ Du80 $=$ duloxetine $80 \mathrm{mg} /$ day $\quad$ q.d., Du60 = duloxetine $60 \mathrm{mg}$ b.i.d. $(120 \mathrm{mg} /$ day $), \mathrm{DMI}=$ desipramine $50 \mathrm{mg}$ b.i.d. ( $100 \mathrm{mg} /$ day). $* p<0.05$ vs placebo, $* * * 0.01$ vs placebo.
$80 \mathrm{mg} /$ day $(+14.6 \mathrm{mmHg}$ vs placebo, $p<0.05)$ at $3 \mathrm{~h}$ postdose, while duloxetine $120 \mathrm{mg} /$ day and desipramine produced no significant changes in SBP. No changes in DBP were detected. At $6 \mathrm{~h}$ postdose, in a standing position, the only significant change observed was a significant increase in HR with desipramine $(+28.2$ vs placebo, $p<0.01)$. Neither dose of duloxetine had any significant effect on HR, and there were no significant effects on SBP or DBP with any of the active doses. No plasma concentrations were obtained at 3 or $6 \mathrm{~h}$ postdose on Day 6 to coincide with collection of cardiovascular measures.

Neither of the duloxetine regimens was associated with significant changes in electrocardiogram parameters (data not shown).

\section{Tyramine Pressor Test}

Mean study drug plasma concentrations measured on Days 7 and 8 before and after the tyramine test are presented in Table 2. Compared to Day 7, Day 8 pretest mean plasma concentrations (more than $24 \mathrm{~h}$ after the last dose) decreased by 61,68 , and $50 \%$ for duloxetine $80 \mathrm{mg} /$ day, duloxetine $120 \mathrm{mg} /$ day, and desipramine, respectively. Mean TYR $\mathrm{PD}_{30}$ values obtained on Days 7 and 8 (as well as comparisons between treatment groups) are shown in Table 3. Mean TYR $\mathrm{PD}_{30}$ was significantly higher after desipramine administration when compared to placebo (30 $v s 7 \mathrm{mg}$, respectively; $p<0.01$ ). No difference was detected between placebo and the duloxetine regimens. On Day 8, TYR $\mathrm{PD}_{30}$ was still significantly increased after desipramine administration when compared to subjects receiving

Table 2 Mean Plasma Concentrations of Study Drugs Before and After Tyramine Pressor Test

\begin{tabular}{|c|c|c|c|c|}
\hline & \multicolumn{2}{|c|}{ Day 7} & \multicolumn{2}{|c|}{ Day 8} \\
\hline & $\begin{array}{l}\text { Pretest } \\
\text { (ng/ml) }\end{array}$ & $\begin{array}{l}\text { Post-test } \\
\text { (ng/ml) }\end{array}$ & $\begin{array}{l}\text { Pretest } \\
\text { (ng/ml) }\end{array}$ & $\begin{array}{c}\text { Post-test } \\
\text { (ng/ml) }\end{array}$ \\
\hline Duloxetine $80 \mathrm{mg}(n=5)$ & $41(8)$ & $49(6)$ & $16(2)$ & $15(2)$ \\
\hline Duloxetine $120 \mathrm{mg}(n=6)$ & $55(5)$ & $66(7)$ & $18(4)$ & $17(3)$ \\
\hline Desipramine $100 \mathrm{mg}(n=\mid \mathrm{I})$ & $55(6)$ & $52(6)$ & $28(4)$ & $27(4)$ \\
\hline
\end{tabular}

Values are presented as mean \pm SEM. The last dose of study drug was administered on Day 7 at $08.00 \mathrm{~h}$.

Table 3 Mean Tyramine $\mathrm{PD}_{30}$

\begin{tabular}{|c|c|c|}
\hline & \multicolumn{2}{|c|}{ TYR PD PD $_{30}(\mathrm{mg})$} \\
\hline & Day 7 & Day 8 \\
\hline Placebo $(n=12)$ & $7[4-14]$ & $6[5-9]$ \\
\hline Duloxetine $80 \mathrm{mg}(n=5)$ & $9[5-8]$ & $7[4-7]$ \\
\hline Duloxetine $120 \mathrm{mg}(n=6)$ & $6[5-9]$ & $4[4-7]$ \\
\hline Desipramine $100 \mathrm{mg}(n=1 \mathrm{I})$ & 30 [22-82] & $\mid 8[|2-3|]$ \\
\hline \multicolumn{3}{|l|}{ Statistical significance ( $p$-value) } \\
\hline Duloxetine 80 vs placebo & 0.29 & 0.71 \\
\hline Duloxetine 120 vs placebo & 0.48 & 0.15 \\
\hline Desipramine 100 vs placebo & $<0.01$ & $<0.01$ \\
\hline
\end{tabular}

TYR PD 30 values presented as 'least squares mean [range]'. The last study dose was administered on Day 7 at $08.00 \mathrm{~h}$. The tyramine test was conducted at 2 and $26 \mathrm{~h}$ after the last study dose. 
placebo $(p<0.01)$. No difference was detected between placebo and the duloxetine regimens.

\section{Safety Profile}

No severe or serious adverse events were reported. Most adverse events reported following dosing with duloxetine, desipramine, or placebo occurred within the first 3 days of study participation and resolved without drug discontinuation or the need for any additional treatment.

\section{Discussion}

Duloxetine dosing induced a decrease in whole-blood 5-HT concentrations after 7 days of treatment. This decrease was significant with duloxetine $120 \mathrm{mg} /$ day dosing but not with duloxetine $80 \mathrm{mg} /$ day. The combined results obtained with the duloxetine regimens were significant, suggesting that duloxetine inhibits platelet 5-HT uptake after 7 days of treatment in young healthy males. This observation is in accordance with previous studies conducted in animals (Wong et al, 1993; Kasamo et al, 1996) and healthy subjects treated with 20 or $60 \mathrm{mg} /$ day of duloxetine (Ishigooka et al, 1997; Turcotte et al, 2001).

Overall, the absolute values reported for urinary output of $\mathrm{NE}$ and its metabolites in placebo-treated patients in the current study agree with previous values reported in the literature, except for MHPG, which tended to be above usual values. During placebo treatment in our study, the mean 24$\mathrm{h}$ MHPG was $21 \mu \mathrm{mol}$, which differs from the mean (7.8 $\mu \mathrm{mol}$ ) found by Linnoila et al (1982). As suggested by higher values found by other groups (Grossman and Potter, 1999), across-study variation is known and often accounted for by differences in assays. The measurements in our study were conducted with an HPLC assay, whereas other reports (Linnoila et al, 1982; Grossman and Potter, 1999) have used GCMS techniques.

The pattern of desipramine effects on urinary excretion of $\mathrm{NE}$ and its major metabolites seen in this study is consistent with an earlier published report (Linnoila et al, 1982). The NE reuptake inhibitor was associated with a significant decrease in whole body NE turnover, as suggested by the decrease in the sum of (NE + NM + VMA + MHPG). Each of the parameters included in this index was significantly decreased following desipramine dosing. The increase in fractional extraneuronal NE concentration was not significant $(p=0.06)$.

Duloxetine was associated with a significant decrease in the major NE metabolites (NM, VMA, MHPG) and in whole body NE turnover. However, duloxetine did not significantly alter NE levels. As seen with desipramine, duloxetine $(80 \mathrm{mg} /$ day or combined regimens) was associated with a similar mean increase in fractional extraneuronal $\mathrm{NE}$ concentration, although the changes did not reach statistical significance ( $p=0.06$ and 0.09 , respectively). An increase in fractional extraneuronal NE concentration suggests either $\mathrm{NE}$ reuptake inhibition and/or decreased intraneuronal NE metabolism. Since duloxetine is not an inhibitor of monoamine oxidase (the enzyme involved in the intraneuronal metabolism of NE) at therapeutic doses (Bymaster et al, 2001), a pharmacological effect on NE reuptake remains the most likely explanation for this finding. An increase in the ratio NM/VMA has been used as an indirect measure of NE reuptake blockade with desipramine (Linnoila et al, 1982). In the present study, this ratio significantly increased with desipramine, whereas with duloxetine the increase was not statistically significant. With desipramine as well as with duloxetine, there were a number of urinary excretion measures suggesting NE reuptake that approached, but did not achieve, statistical significance. The capacity to detect significance in these measures may have been affected by the small sample size in this study.

Both desipramine and duloxetine $80 \mathrm{mg} /$ day had statistically significant effects on HR when measurements were taken with subjects in the standing position on Day 6 . The most plausible explanation is that these agents produced sympathetic potentiation by NE reuptake inhibition. In theory, sympathetic potentiation would be expected to result in an increase in both $\mathrm{HR}$ and BP. However, desipramine and duloxetine had different cardiovascular patterns at steady state in healthy subjects. When subjects were standing, desipramine significantly increased $\mathrm{HR}$ at the three time points without affecting BP, whereas duloxetine $80 \mathrm{mg} /$ day was associated with a combined increase in HR and SBP at $3 \mathrm{~h}$ postdose. The lack of effect of desipramine on BP is usually attributed to a concurrent $\alpha_{1}$-adrenoceptor blockade, which may counteract the pressor effect resulting from NE uptake blockade (Glassman, 1984).

In larger, long-term clinical trials in depressed patients, small, not clinically significant, but statistically significant changes relative to placebo were seen in HR and BP with duloxetine doses of $60-120 \mathrm{mg} /$ day (Goldstein et al, 2002; Detke et al, 2002a, b). Therefore, it was unexpected when, in the current study, treatment with duloxetine $120 \mathrm{mg} /$ day did not produce significant changes in cardiovascular parameters, particularly while significant cardiovascular effects were detected with duloxetine $80 \mathrm{mg} /$ day. The duloxetine dosing scheme used in this study provides one possible explanation for these findings. While the $80 \mathrm{mg} /$ day dose was administered in a single morning dose, the $120 \mathrm{mg} /$ day dose was given in two daily doses of $60 \mathrm{mg}$ each. When comparing the steady-state plasma concentrations of drug with the plasma concentrations collected before and after the tyramine pressor test on Day 7 (postdose), there is an apparent increase in plasma concentrations of duloxetine postdose that is relatively greater for duloxetine $80 \mathrm{mg} /$ day than for duloxetine $120 \mathrm{mg} /$ day. It may be that the cardiovascular changes seen with duloxetine $80 \mathrm{mg} /$ day were more likely an immediate response to the preceding dose than a response to steady-state levels of drug. However, we cannot confirm that any transient increase in plasma drug levels coincided with increases in cardiovascular parameters since concurrent measures of the two were not collected. Moreover, this theory does not explain why a significant increase in supine SBP was detected with duloxetine $80 \mathrm{mg} /$ day, but not with duloxetine $120 \mathrm{mg} /$ day at $0 \mathrm{~h}$. Perhaps a counter-regulatory system exists which is more effective in the presence of higher plasma concentrations of duloxetine.

Desipramine, a potent NE reuptake inhibitor with minimal effects on 5-HT reuptake process in in vitro assays (Bolden-Watson and Richelson, 1993; Owens et al, 1997), 
was selected as a positive control in our study on the basis of its documented effect on the tyramine pressor test. Earlier observations in healthy volunteers had shown that desipramine induces a significant rightward shift (ie decreased sensitivity) of the tyramine dose-response curve after a single oral dose of $50 \mathrm{mg}$ (McEwen, 1977; Ghose et al, 1976; Jackson et al, 1983) and after multiple doses (Debonnel et al, 1998). The two- to three-fold shift of the tyramine dose-response curve (corresponding to a $22 \mathrm{mg}$ increase in TYR $\mathrm{PD}_{30}$ ) observed in our study, after 7 days of administration, is consistent with the results of these earlier studies. We also found a smaller, but still significantly decreased, sensitivity to the pressor effect of tyramine on Day 8, when the concentration was $50 \%$ of that observed on Day 7.

In the current study, duloxetine did not significantly affect the pressor response to tyramine, a finding that contrasts with the drug's effect on urinary metabolic parameters and various cardiovascular measures. The lack of effect seen in the tyramine pressor test could be explained by several mechanisms. First, since duloxetine is $90-95 \%$ plasma protein bound (Lilly Research Laboratories, data on file), it could be argued that insufficient free plasma concentrations of duloxetine for NET inhibition were achieved peripherally. However, in the present study, the average steady-state plasma concentrations achieved with the two regimens (40-70 ng/ml, approximately $120-210 \mathrm{nM}$ ) were associated with significant alterations in urinary excretion, suggesting either central and/or peripheral NE reuptake blockade. More specifically, duloxetine was associated with a significant decrease in urinary excretion of MHPG. Since urinary MHPG has been proposed as an index reflecting central turnover of NE (Maas and Leckman 1983), our data would be consistent with an effect on central nervous system NE synthesis and turnover. It should be noted, however, that decreased turnover of $\mathrm{NE}$ is also observed after several weeks of administration of 5-HTspecific reuptake inhibitors (SSRIs), as evidenced by decreased MHPG in the cerebrospinal fluid (Bjerkenstedt et al, 1985; De Bellis et al, 1993; Potter et al, 1985; Rudorfer et al, 1984; Sheline et al, 1997). Whether such decreases occur after 1 week of administration of an SSRI is not known. Nevertheless, when compared with the effect on peripheral reuptake of 5-HT, there is also an indirect argument in favor of effective NET blockade. In healthy subjects, 5-HT reuptake inhibition has been shown to occur with duloxetine at average steady-state plasma concentrations as low as $6-9 \mathrm{ng} / \mathrm{ml}$ (approximately 18-27 nM) (Turcotte et al, 2001). Animal studies have shown duloxetine to be approximately 3.5 times as potent in blocking 5-HT reuptake as it is in blocking NE reuptake (Wong et al, 1993; Kasamo et al, 1996). Thus, the circulating concentrations of duloxetine observed in the current study should, in theory, be associated with peripheral NET inhibition.

Another possible explanation for the absence of significant effect on the tyramine pressor test could be that duloxetine may desensitize the myocardial $\beta_{1}$-adrenoceptors believed to mediate the pressor effects of tyramine in humans (Scriven et al, 1984; Colombo et al, 1988). Basal sympathetic nervous system activity would be increased by chronic NET inhibition. As a consequence, $\beta_{1}$-adrenocep- tors may become desensitized and/or downregulated, resulting in reduced sympathetic nervous system responses during additional $\beta$-adrenergic stimulation. However, it is unclear why this desensitization and/or downregulation would occur only with duloxetine and not with desipramine.

Turcotte et al (2001) proposed that the dual 5-HT/NE reuptake inhibitors venlafaxine and duloxetine could interact with a different NET from that which responds to tricyclic antidepressants. Human studies conducted with venlafaxine suggest that such compounds could have a modest effect on the tyramine pressor response when compared to specific NE reuptake inhibitors such as desipramine. In addition, a modest but significant decrease in sensitivity to tyramine was observed with venlafaxine, using only two challenge doses of tyramine, in a group of 22 depressed patients treated with $225 \mathrm{mg}$ /day venlafaxine, but the decrease in sensitivity was not seen in six healthy subjects treated with $300 \mathrm{mg} /$ day (Debonnel et al, 1998). These findings might suggest that a larger sample size is required to reproduce the effect detected in depressed patients. Alternatively, there may be important differences that exist between the properties of the NET in depression and normalcy; an early study in which individuals with depressive illness were shown to have a greater pressor response to tyramine in comparison to nondepressed subjects further supports this premise (Ghose and Turner, 1975).

Recently, pressor responses to intravenous tyramine were studied in healthy subjects after 2 weeks of treatment with venlafaxine 75 or $375 \mathrm{mg} /$ day, sertraline $50 \mathrm{mg} /$ day (specific 5-HT reuptake inhibitor), or maprotiline $150 \mathrm{mg} /$ day (NE uptake inhibitor) (Harvey et al, 2000). Sertraline, a 5-HT reuptake inhibitor, induced a leftward shift of the doseresponse curve to tyramine, as did the lower dose of venlafaxine, which inhibits NE reuptake at higher doses only. Moreover, the effect of high-dose venlafaxine on the tyramine challenge in this study was reduced in comparison to the NE-specific reuptake inhibitor maprotiline. These data suggest that 5 -HT reuptake inhibition might enhance the pressor response to tyramine, masking the expected decrease due to NE reuptake inhibition (Chalon et al, 2002).

In summary, the assays used in the present study support the conclusion that duloxetine impacts both peripheral 5$\mathrm{HT}$ and NE reuptake in vivo. The NE metabolite assays in which duloxetine is active may be more sensitive to uptake blockade than the tyramine pressor test, which requires exogenously added compound. In addition, the tyramine test may not be the most appropriate tool to measure NE reuptake blockade in healthy subjects in the presence of some dual 5-HT/NE reuptake inhibitors. In the light of these findings, we suggest that better methods to evaluate $\mathrm{NE}$ reuptake in humans are required. One possibility is the development of a ligand for NE for use in positron emission tomography (PET), a novel technique that is currently being used to image serotonin transporter sites blocked by SSRIs.

\section{ACKNOWLEDGEMENTS}

We thank Ken Perry (Lilly Research Laboratories, Indianapolis, IN, USA) for performing the whole-blood serotonin 
measurements and Jean-Marie Dethy (Lilly Research Laboratories, Mont-Saint-Guibert, Belgium) for comments on the manuscript. We also thank Michel Guillaume, MD, of Aster-Cephac (Paris, France).

All authors, with the exception of Christine Hirth, are employees of Eli Lilly and Company or were at the time this study was conducted.

\section{REFERENCES}

Bjerkenstedt L, Edman G, Flyckt L, Hagenfeldt L, Sedvall G, Wiesel FA (1985). Clinical and biochemical effects of citalopram, a selective 5-HT reuptake inhibitor - a dose-response study in depressed patients. Psychopharmacology (Berl) 87: 253-259.

Bolden-Watson C, Richelson E (1993). Blockade by newlydeveloped antidepressants of biogenic amine uptake into rat brain synaptosomes. Life Sci 52: 1023-1029.

Bourdeaux R, Capolaghi B, Lacroix C, Younos C, Lehr PR (1995). Assay of urinary free and conjugated 3-methoxy-4-hydroxyphenylethyleneglycol by high-performance liquid chromatography with amperometric detection. J Chromatogr B Biomed Appl 665 45-51.

Bymaster FP, Dreshfield-Ahmad LJ, Threlkeld PG, Shaw JL, Thompson L, Nelson DL, Hemrick-Luecke SK, Wong DT (2001). Comparative affinity of duloxetine and venlafaxine for serotonin and norepinephrine transporters in vitro and in vivo, human serotonin receptor subtypes, and other neuronal receptors. Neuropsychopharmacology 25: 871-880.

Chalon S, Bieck PR, Goldstein DJ, Detke MJ, Bymaster FP, Potter WZ, Demitrack MA (2002). The tyramine pressor test may have limited sensitivity, especially in the presence of dual serotonin/ norepinephrine uptake inhibition. Neuropsychopharmacology 26: 698-699.

Colombo F, Sega R, Mailland F, Rigo R, Palvarini L, Libretti A (1988). Beta-blockade antagonism of tyramine-induced rise in blood pressure. Eur J Clin Pharmacol 34: 263-266.

De Bellis MD, Geracioti Jr TD, Altemus M, Kling MA (1993). Cerebrospinal fluid monoamine metabolites in fluoxetinetreated patients with major depression and in healthy volunteers. Biol Psychiatry 33: 636-641.

Debonnel G, Blier P, St-André E, Hebert C, de Montigny C (1998). Comparison of the effect of low and high doses of venlafaxine on serotonin and norepinephrine reuptake processes in patients with major depression and healthy volunteers. Int J Neuropsychopharmacol 1(Suppl 1): 17-1.

Detke MJ, Lu Y, Goldstein DJ, Hayes JR, Demitrack MA (2002a). Duloxetine, $60 \mathrm{mg}$ once daily, for major depressive disorder: a randomized double-blind placebo-controlled trial. J Clin Psychiatry 63: 308-315.

Detke MJ, Lu Y, Goldstein DJ, McNamara RK, Demitrack MA (2002b). Duloxetine $60 \mathrm{mg}$ once daily dosing versus placebo in the acute treatment of major depression. J Psychiatr Res 36: 383390.

Engleman EA, Perry KW, Mayle DA, Wong DT (1995). Simultaneous increases of extracellular monoamines in microdialysates from hypothalamus of conscious rats by duloxetine, a dual serotonin and norepinephrine uptake inhibitor. Neuropsychopharmacology 12: 287-295.

Ghose K, Gifford LA, Turner P, Leighton M (1976). Studies of the interaction of desmethylimipramine with tyramine in man after a single oral dose, and its correlation with plasma concentration. Br J Clin Pharmacol 3: 334-337.

Ghose K, Turner P (1975). Intravenous tyramine pressor response in depression. Lancet 1: 1317-1318.

Gironi A, Seghieri G, Niccolai M, Mammini P (1988). Simultaneous liquid-chromatographic determination of urinary vanillylman- delic acid, homovanillic acid, and 5-hydroxyindoleacetic acid. Clin Chem 34: 2504-2506.

Glassman AH (1984). Cardiovascular effects of tricyclic antidepressants. Annu Rev Med 35: 503-511.

Goldstein DJ, Mallinckrodt C, Lu Y, Demitrack MA (2002). Duloxetine in the treatment of major depressive disorder: a double-blind clinical trial. J Clin Psychiatry 63: 225-231.

Grossman F, Potter WZ (1999). Catecholamines in depression: a cumulative study of urinary norepinephrine and its major metabolites in unipolar and bipolar depressed patients versus healthy volunteers at the NIMH. Psychiatry Res 87: 21-27.

Harvey AT, Rudolph RL, Preskorn SH (2000). Evidence of the dual mechanisms of action of venlafaxine. Arch Gen Psychiatry 57: 503-509.

Ishigooka J, Nagata E, Takahashi A, Sugiyama T, Uciumi M, Tsukahara T (1997). Simultaneous monitoring of inhibition of serotonin uptake by platelets and plasma drug concentrations following administration of duloxetine, a new antidepressant candidate, to healthy volunteers. Curr Ther Res 10: 679-692.

Jackson SH, Turner P, Ehsanullah RS (1983). A comparison of diclofensine and desmethylimipramine using tyramine pressor tests in normal subjects. Br J Clin Pharmacol 16: 427-429.

Kasamo K, Blier P, de Montigny C (1996). Blockade of the serotonin and norepinephrine uptake processes by duloxetine: in vitro and in vivo studies in the rat brain. J Pharmacol Exp Ther 277: 278-286.

Katoh A, Eigyo M, Ishibashi C, Naitoh Y, Takeuchi M, Ibii N et al (1995). Behavioral and electroencephalographic properties of duloxetine (LY248686), a reuptake inhibitor of norepinephrine and serotonin, in mice and rats. J Pharmacol Exp Ther 272: 1067-1075.

Kihara T, Ikeda M (1995). Effects of duloxetine, a new serotonin and norepinephrine uptake inhibitor, on extracellular monoamine levels in rat frontal cortex. J Pharmacol Exp Ther 272: 177-183.

Li XM, Perry KW, Wong DT, Bymaster FP (1998). Olanzapine increases in vivo dopamine and norepinephrine release in rat prefrontal cortex, nucleus accumbens and striatum. Psychopharmacology 136: 153-161.

Linnoila M, Karoum F, Calil HM, Kopin IJ, Potter WZ (1982). Alteration of norepinephrine metabolism with desipramine and zimelidine in depressed patients. Arch Gen Psychiatry 39: 10251028.

Maas JW, Leckman JF (1983). Relationship between central nervous system noradrenergic function and plasma and urinary MHPG and other norepinephrine metabolites. In: Maas JW (eds) MHPG: Basic Mechanisms and Psychopathology. Academic Press: London. pp 33-44.

Marshall EF, Kennedy WN, Eccleston D (1987). Whole blood serotonin and plasma tryptophan using high-pressure liquid chromatography with electrochemical detection. Biochem Med Metab 37: 81-86.

McEwen J (1977). Influence of nomifensine and desipramine on tyramine pressor responses in healthy volunteers. $\mathrm{Br} \mathrm{J} \mathrm{Clin}$ Pharmacol 4(Suppl 2): 157S-158S.

Owens MJ, Morgan WN, Plott SJ, Nemeroff CB (1997). Neurotransmitter receptor and transporter binding profile of antidepressants and their metabolites. J Pharmacol Exp Ther 283: $1305-1322$.

Pace DG, Reele SB, Rozik LM, Rogers-Phillips CA, Dabice JA, Givens SV (1988). Evaluation of methods of administering tyramine to raise systolic blood pressure. Clin Pharmacol Ther 44: 137-144.

Potter WZ, Scheinin M, Golden RN, Rudorfer MV, Cowdry RW, Calil HM et al (1985). Selective antidepressants and cerebrospinal fluid. Lack of specifity on norepinephrine and serotonin metabolites. Arch Gen Psychiatry 42: 1171-1177. 
Reimann IW, Firkusny L, Antonin KH, Bieck PR (1993). Oxaprotiline: enantioselective noradrenaline uptake inhibition indicated by intravenous amine pressor tests but not alpha 2-adrenoceptor binding to intact platelets in man. Eur J Clin Pharmacol 44: 9395.

Rudorfer MV, Scheinin M, Karoum F, Ross RJ, Potter WZ, Linnoila $M$ (1984). Reduction of norepinephrine turnover by serotonergic drug in man. Biol Psychiatry 19: 179-193.

Scriven AJ, Brown MJ, Murphy MB, Dollery CT (1984). Changes in blood pressure and plasma catecholamines caused by tyramine and cold exposure. J Cardiovasc Pharmacol 6: 954-960.

Sharma A, Goldberg MJ, Cerimele BJ (2000). Pharmacokinetics and safety of duloxetine, a dual-serotonin and norepinephrine reuptake inhibitor. J Clin Pharmacol 40: 161-167.

Sheline Y, Bardgett ME, Csernansky JG (1997). Correlated reductions in cerebrospinal fluid 5-HIAA and MHPG concentrations after treatment with selective serotonin reuptake inhibitors. J Clin Psychopharmacol 17: 11-14.
Turcotte JE, Debonnel G, de Montigny C, Hebert C, Blier P (2001). Assessment of the serotonin and norepinephrine reuptake blocking properties of duloxetine in healthy subjects. Neuropsychopharmacology 24: 511-521.

Volin P (1994). Determination of free urinary catecholamines by high-performance liquid chromatography with electrochemical detection. J Chromatogr B Biomed Appl 655: 121-126.

Wong DT (1998). Duloxetine (LY 248686): an inhibitor of serotonin and noradrenaline uptake and an antidepressant drug candidate. Exp Opin Invest Drugs 7: 1691-1699.

Wong DT, Bymaster FP (2002). Dual serotonin and noradrenaline uptake inhibitor class of antidepressants potential for greater efficacy or just hype? Prog Drug Res 58: 169-222.

Wong DT, Bymaster FP, Mayle DA, Reid LR, Krushinski JH, Robertson DW (1993). LY248686, a new inhibitor of serotonin and norepinephrine uptake. Neuropsychopharmacology 8: 23-33. 